\title{
A Trinity of Reading, Peer Cooperation, and Consciousness Raising for Meaningful Revision under the Guidance of Social Constructivism*
}

\author{
Tiemei Guo \\ Dalian Polytechnic University \\ Dalian, China
}

\begin{abstract}
Writing is negotiation of meaning between writer and reader through interaction and revision is the regeneration of meaning when the negotiation is threatened or unable to be accomplished. In nature, revision is meaningful only when it is based on the interaction between reader and writer. In the case of revision instruction of non-English majors in China, the paper puts forward a trinity to this problem on the basis of the social constructive model of teaching and learning: revision through critical reading, peer cooperation and consciousness rising.
\end{abstract}

Keywords-revision; social constructivism; critical reading; peer cooperation; consciousness raising

\section{INTRODUCTION}

Though revision was often defined as the last stage in the writing process, it is now generally accepted that the most outstanding feature of writing is recursion (see for example, Flower \& Hayes, 1981; Zamel, 1982). Writing is rewriting (Murray, 1982). Therefore, "......the teaching of writing in that revision has assumed a position of central importance" (Zamel, 1982, p.34).

However, the situation is not optimistic in China. Writing has long been playing a negligible role in the English instruction to the non-English majors at tertiary level, and it is even worse in the case of revision. "Only when we understand the multidimensional nature of revision, can we better teach revising as a rhetorical concern" (Faigley \& Witte, 1981, p.21). The focuses of learning are not only on the mechanics of the basic conventions of written language, but the uses of writing in creating a more thoughtful citizenry. Students must learn not only how to manage the basics of writing but also how to use what they already know to shape and rethink their ideas, in one word, to construct knowledge meaningful to themselves.

So, not to make a bold systematic theoretical definition on revision, the aim of this thesis is to understand the nature of revision on the basis of social-constructivism, to explore

*Supported by Fundamental Research Program of Higher Education of Liaoning Province (2017J019) its implications to ESL writing class for non-English majors of tertiary level, and to suggest some tentative practical solutions to the problem.

\section{WRITING TEACHING AND LEARNING AT TERTIARY LEVEL IN CHINA}

Writing is given a relatively high priority for the College English bands (College English Syllabus 2001, compared to that in 1991), however, in practice and in effect, writing teaching and learning assumes a low priority and efficiency.

\section{A. Teaching Activities in Writing Class}

Some teachers do not bother to teach writing in class and they believe writing can be left to take care of itself since writing is supposed to be the natural consequence of vocabulary, grammar, and structure patterns etc. Consequently, the students are not especially interested in quality of ideas or expression but primarily concerned with formal linguistic features.

Another common practice for teaching writing in colleges is teachers provide students with a form to have students operate with. At the most complex, teachers ask students (always provided with a topic) to list and group relevant facts, derive topic and supporting sentences from these facts, assemble an outline, and write their compositions from outline. After students' product turned in, teachers still respond to and concern with the logical construction and arrangement of discourse form.

In recent years, some teachers make tentative efforts to adopt the process approach into ESL composition classroom. However, the tentative efforts turned to be invalid in that teachers cannot allocate ample time to develop students' composing process from the crowded lesson schedule. Moreover, teachers' minimal interference tends to lead the classroom out of control. Besides, facing such oversize classes, teachers feel helpless to give constructive and effective face-to-face response and instruction. In addition, students found to follow an orderly procedure as they write lose their train of thought because they spend so much of 
their energy during composing attending to mechanical concern. Thus teachers return to their traditional way.

\section{B. Students' False Perceptions about English Writing}

Most students hold a false belief that learning a foreign language means learning grammatical rules, remembering words and memorizing structures and patterns, and that writing is not as important as reading. These perceptions about English writing greatly influence how they deal with their learning tasks and this in turn influences their development of different language skills. For example, even if students are given time for practicing writing in the classroom, they do not take it seriously and make efforts towards this end.

\section{Low-productive Feedback}

Facing more than 100 drafts, teachers' response always focus on form, which result in students' illusion that form is the central concern of writing. Besides, teachers focus their responses on the same concerns, vocabulary, structure, grammar, logic, etc., in the same way, regardless of differences between individual students and their work.

\section{Textbooks under Traditional Theoretical Guidance}

It is found in the textbooks that writing instruction is designed from how to write grammatical sentences to construct cohesive paragraphs, and then to invent a whole article with one central idea. The focus is obviously on how to equip students with suitable forms and mechanics, whereas, other aspects of writing are ignored, for example, writing purpose, audience, writing strategies, writing processes, etc.

From the above descriptions of the situation of English writing teaching in colleges for non-English majors, it is not difficult for us to see why students take revision as revising form instead of meaning.

\section{REVISION AS REGENERATING MEANINGS THROUGH SOCIAL INTERACTION}

Social constructivism, is a psychological educational theory which originated in the West in 1980s. Because it incorporates various theories of multi disciplines to enrich its contents, it has been become the leading theory to be used to interpret various fields.

\section{A. The General Sketch of Social Constructivism}

Owing to its scientific interpretations on education and its increasing enrichment and perfection through incorporating the cores of multi disciplines, such as psychology, philosophy, cognitive science, educational theories, etc., social-constructivism, has shown great impact on various fields, especially on language education, and it has become the main stream theory in academic world.

The philosophical roots of social constructivism lie in the work of Wittgenstein (1953) and Mead (1943), which has been further articulated in the work of Harre (1984). Social constructivists also takes the social interaction theory as its frame, which originated from the theories of Vygotsky (1962 1978), that is, knowledge is constructed by interactions of individuals with the society and that all thought is social in nature; meanwhile it assimilates the cream of multidisciplines as constructivism, humanism, information processing theory of cognitivism and social-interactionism to get itself sophisticated.

Cognitive approaches emphasize the importance of what the learner brings to any learning situation as an active meaning-maker and problem-solver. Thus, the learner plays a central role in social-constructive model. Humanistic approaches emphasize also the development of the whole person in educational settings and suggest that language teaching/learning can and should be seen in this light. Social interactionism emphasizes the dynamic nature of the interplay between teachers, learners and tasks, and provides a view of learning as arising from interactions with others.

In short, for social-constructivism, knowledge is constructed through social interaction by individuals, which doesn't exist independently of the individuals. In other words, knowledge cannot be put into the learner's mind by the force out of the learner, but is constructed subjectively by the individuals in the way meaningful to themselves.

\section{B. Revision as Regenerating Meaning through Social Interaction}

If writing is seen as negotiation of meaning between reader and writer, then revision occurs when the convergence between them is on threatened, or not accomplished, since writers and readers seek to orient themselves to a projected state of convergence between them. Then revision will be regenerating meaning according to the communicative need of writers to balance their own purposes and intentions with the expectations and needs of readers. So, from this sense, the nature of revision is still social-interaction.

Writers identify potential trouble sources. That is, the overarching goal of writers is to achieve reciprocity, or a state of convergence with readers. They monitor their texts for the extent to which reciprocity seems threatened. Revision is initiated if the projected state of convergence may be threatened. Writers make choices about how to treat potential trouble sources. Writers make appropriate elaborations and, restore a temporarily shared social reality changes.

Then revision will be regenerating meaning according to the communicative need of writers to balance their own purposes and intentions with the expectations and needs of readers. So the reviser is more likely to learn what and how to revise through the actual practice of writing within a community of readers and writers. Thus, knowing about revision tends to be viewed as a situation-dependent constructive process among minds. 
IV. A TRINITY OF READING, PEER COOPERATION, AND CONSCIOUSNESS RAISING TO MEANINGFUL REVISION UNDER THE GUIDANCE OF SOCIAL CONSTRUCTIVISM

Drawing insights from the past researches on revision enhancement and the social constructive model of teaching and learning, considering the specific situations of English writing for non-English majors of tertiary level in China, a trinity approach of reading, peer working, and development of the learner's critical language awareness for meaningful revision is proposed.

\section{A. Revision through Critical Reading}

Reading and writing are interrelated. Theorists insist that the text, the reader, and the writer are negotiating each other interactively. Reading and writing become recursive, reciprocal, and mutually dependent acts.

Revision as regenerating meaning occurs when the negotiation between reader and writer is threatened or not accomplished. Then for the reader, the reading process is "a delicate balance between the sources of constructive freedom and forces that seek to constrain" (Brent, 1992, p. 44). For the writer, he must manipulate a text "according to his estimate of the reader's repertoire and situation" (Brent, 1992, p. 45). Revision is just to keep this "delicate balance". So through reading, our students can recognize and analyze the "delicate balance", and therefore they will gain a more profound insight into the production of texts and the control of meaning---insight that cannot help but make them more effective writers.

So first, our students need to understand that as readers they always actively constitute meaning, not just receiving information. Furthermore, by our student readers being more aware of their own experience of reading, we can make them better aware of the ways in which their own texts communicate.

Second, our students should recognize that their expectations of a text often shape their responses to it. Audience-oriented explanations of the reading process remind us that what readers know and believe and what they have been told about texts determine in large part how they respond to a text. To read not by the measure of what "should" be read, but to ask how and why, allows readers find a new inter textual basis for relationships between texts.

Third, as teachers we must decide why we want students to read a particular text, and we must communicate that purpose explicitly. That our motives may be various---and that different texts offer students a different piece of the puzzle that is reading and writing - are without doubt, and we should make those differences clear in the way we present texts to students. We must do more than merely provide students with clues that help them contextualize a text. We must help students understand for themselves that how specific kinds reading and writing relate, and how they are alike and how they are different.

Since the most important English course in Chinese tertiary institutions is reading, we can use these reading texts as resources for teaching writing and revision so that we can solve the problem of busy schedule, help the students to make meaningful reading, and therefore help them make meaningful revision.

\section{B. Revision through Cooperation}

Because in the social constructive view of writing, knowledge is a socially constructed artifact (cf. Bruffee, 1984, 1986), one acquires knowledge about writing in contexts, which is in the context of communities of writers and readers, and revision as well. Then peer interaction is taken as a necessity.

A social constructivist view of learning has its philosophical roots in the work of Wittgenstein (1953) and Mead (1934) and has been further articulated in the work of Harre (1984). These philosophers share with Kuhn (1962) the conceptualization of knowledge as a social artifact that is maintained through a community of peers. Knowledge, then is not based on objective reality that can be measured and quantified but rather is consensually formed through social interaction (Bruffee, 1984, 1986).

The connections between revision and cooperation can be clearly linked. Since writing is negotiating meanings between writer and reader; revision occurs when the convergence of meanings between writer and reader is threatened or unable to be accomplished. Through working collaboratively with readers writers can make clear of what readers expect and keep confused about, and therefore the mutual understanding is constructed. Research focusing specifically on revision when peers respond to and edit writing has revealed that students can help one another improve their writing through response.

Moreover, in a realistic situation, a group of members contribute different aspects of knowledge, various understandings, different commands of target language, etc. which inevitably needs both knowledge transmission and transformation.

Through peer operation, revision becomes a meaningful way for both the reader and writer to construct knowledge meaningful to them in that they can control and direct their study, and get immediate feedback in a cooperative, friendly atmosphere with the least tension and pressure. Besides by revision through peer operation, these often ignored aspects of writing, for example, audience, writing purpose are also made clear by the communication with each other. And also, incorporated the textual attributes and procedural knowledge, learners grow to grasp the procedural skill and ability to negotiate the universe. By this way students can foster their own responsibilities to study, turn from a passive learner into an autonomic learner, and lay foundation for their life long study.

\section{Revision by Conscious Raising}

Consciousness plays a very important role in language learning. Schmidt (1994) distinguishes 4 common senses of consciousness: 1) consciousness as intention; 2) consciousness as attention; 3) consciousness as awareness; 4) consciousness as control. However, Vygosky's definition has 
a crucial place in language learning, which is 'the objectively observable organization of behavior that is imposed on humans through participation in sociocultural practices.

Our goal of education is whole person involvement education, which embodies this notion: learners take control of their learning, and direct their learning even after school. So the fourth level of consciousness is just the ultimate plane that learners are supposed to reach. In other words, learning occurs when learners chose to learn, which suggests an affective domain of social constructivism; then he or she will notice or focus what interests him or rather is meaningful to him, which indicates both affective and cognitive domain; then they have the knowledge of the target through interaction with others in a community; and at last they construct their knowledge based on their original knowledge and the knowledge becomes automatized one.

So it is self-evident that why we should raise learners' consciousness during revision. Learning takes place in the only case of consciousness. Without subjective motivation, it is impossible for learners to revise; without noticing and focusing, learners have nothing to revise; without knowing the rules, learners are unable decide how to revise; and naturally revision can't go without the above phases of consciousness.

\section{The Integration of the Three Approaches to Revision in English Class for Non-English Majors}

For the class the central activity is peer working. Through cooperation, learners can trigger their interests in reading and writing, foster their responsibility to their own learning, and increase their motivation to learn due to selfdetermination, which indicates learners are "sentimentally" ready to negotiate meaning with the text, the reader, and the writer. Besides, due to the need to integrate new or conflicting information brought to learners by other group members, cognitive restructuring and reprocessing consequently occur, which shows by peer working learners get access to the procedural knowledge and skills. And in this process learners share a common fate and striving for mutual benefits, by which learners are equipped with the knowledge of "the interactive motives of the universe and that authors and readers seek each other within a system of common understanding. By critical reading, learners can not only construct their understanding to textual attributes, but also gain a more profound insight into the production of texts and the control of meaning---insight that cannot help but make them more effective writers. By raising their consciousness, we can make learners aware of the writing mechanics, or "textual attributes", and provide a basis for learners to interact.

\section{CONCLUSION}

Just as what we have talked about, English writing has long been ignored in Chinese tertiary level English teaching, and it is even worse for revision. However, the most significant feature of writing is recursion, which suggests the central role that revision plays during writing instruction. However, the seemingly ignorance of revision, as a matter of fact, reflects teachers' theoretical beliefs on writing and revision, which are the greatest influential power on learners. No matter how the teacher adopts new instructional approaches, what really count are her or his beliefs about writing, and about the educational philosophy.

For a reflective teacher, most interesting to her is an educational technology which helps students to become aware of their own intuitive understandings, to fall into cognitive confusions and explore new direction of understanding and action, which embodies the spirit of social constructivist view: learners actively make sense of the world through interaction with other people in ways meaningful to them.

Besides, the different social context leads to different teaching approaches. By giving a model to teach revision in the class, the author wants to make tentative efforts to arouse the brainstorming on this issue. What is significant to teachers is to foster the right climate for learning to take place, for confidence to develop, for people's individuality to be respected, for a sense of belonging to be nurtured, for developing appropriate learning strategies, and for moving towards learner autonomy.

\section{REFERENCES}

[1] Brent, D. (1992). Reading as rhetorical invention: knowledge, persuasion, and the teaching of research based writing. Urbara, IL: National Council of Teachers of English.

[2] Bruffee, K.A. (1984). Collaborative learning and the "conversation of mankind." College English, 34, 634-643.

[3] Bruffee, K.A. (1986). Social construction, language and the authority of knowledge: A bibliographical essay. College English, 48, 773-790.

[4] Faigley, L., \& Witte, S. (1981). Analyzing revision. College Composition and Communication, 32, 400-414.

[5] Flower, L., \& Hayes, J.R.(1981). A cognitive process theory of writing. College Composition and Communication, 32 (4), 365-287.

[6] Harre, R. (1984). Personal being: A theory for individual psychology. Cambridge: Harvard University Press.

[7] Kuhn, T. (1962). The structure of scientific revolutions. Chicago: University of Chicago Press.

[8] Mead, G.H. (1934). Mind, self, and society from the standpoint of a social behaviorist. Chicago: University of Chicago Press.

[9] Vygotsky, L.S. (1962). Thought and Language. Cambridge, Mass: MIT Press.

[10] Vygotsky, L.S. (1978). Mind and society: The development of higher psychological processes. Cambridge: Harvard University Press.

[11] Wittgenstein, L. (1953). Philosophical investigation. New York: Macmillan.

[12] Zamel, V. (1982). Writing: the process of discovering meaning. TESOL Quarterly, 16 (2), 195-207. 